\title{
Repurposing of FDA Approved Alkaloids as COVID 19 Inhibitors; In Silico Studies
}

\author{
Ehab M. Mostafa ${ }^{1}$, Mohammed Gamal ${ }^{2}$, Mohammed M. Ghoneim ${ }^{3}$, Shaimaa Hussein ${ }^{4}$, Ahmed H. El-Ghorab ${ }^{5}$, \\ Mohamed A. Abdelgawad ${ }^{2, *}$, Arafa Musa ${ }^{1}$
}

\section{Ehab M. Mostafa ${ }^{1}$, Mohammed \\ Gamal', Mohammed M. \\ Ghoneim ${ }^{3}$, Shaimaa Hussein ${ }^{4}$, Ahmed H. El-Ghorab ${ }^{5}$, Mohamed \\ A. Abdelgawad ${ }^{2, *}$, Arafa Musa ${ }^{1}$}

'Pharmacognosy Department, College of Pharmacy, Jouf University, Sakaka, Aljouf, 72341, KSA.

${ }^{2}$ Department of Pharmaceutical Chemistry, College of Pharmacy, Jouf University, Sakaka 72341, KSA.

${ }^{3}$ Department of Pharmacy, College of Pharmacy, Al Maarefa University, Ad Diriyah 13713, SAUDI ARABIA.

${ }^{4}$ Department of Pharmacology, College of

Pharmacy, Jouf University, Sakaka, Aljouf

72341, SAUDI ARABIA

${ }^{5}$ Chemistry Department, College of Science, Jouf university, Sakaka, Aljouf 72341, SAUDI ARABIA.

\section{Correspondence}

Mohamed A. Abdelgawad, PhD

Department of Pharmaceutical Chemistry, College of Pharmacy, Jouf University,

Sakaka, 72341, KSA.

Phone no: (+966)-595435214

E-mail: mhmdgwd@ju.edu.sa,

mohamedabdelwahab976@yahoo.com

\section{History}

- Submission Date: 26-10-2020;

- Review completed: 22-11-2020;

- Accepted Date: 01-12-2020.

DOI : 10.5530/pj.2021.13.16

Article Available online

http://www.phcogj.com/v13/i1

Copyright

(C) 2021 Phcogj.Com. This is an openaccess article distributed under the terms of the Creative Commons Attribution 4.0 International license.

\section{ABSTRACT}

Background: Alkaloid drugs were permitted for using as a treatment of numerous diseases Colchicine, codeine, piperine, papaverine, ergometrine, theophylline, theobromine and caffeine are recognized safe alkaloids and used for many human disfunctions. The chemical structures of alkaloids have flexible chemical moieties with various electronic and chemical characters. COVID-19 is a horrible disease as result from that the discovering of potent drugs from previously FDA approved drugs is the main objective of this study. Methods: docking studies were used for discovering the interactions of alkaloids with protease proteins. The nature of selected alkaloids structures was utilized for advance insights studies to predict new medical applications. Results: Docking studies for alkaloids were completed and the obtained outcomes, displayed that all tried alkaloids have great attraction with the five protease proteins, the energy docking score ranged from -2.9516 (for colchicine with $5 R 82$ ) to -24.7449 (for ergotamine with $5 \mathrm{R} 80$ ) $\mathrm{kcal} / \mathrm{mol}$ with $1-5$ variable interactions bond. Conclusion: Among the tested drugs, papaverine and ergometrine revealed high docking scores for all five proteins (score ranged from, -14.1058 to 23.1619 for papaverine and, -4.7900 to 24.7449 for ergometrine) and number of interactions with all tested proteins are two to three for papaverine but for ergometrine are two to five.

Key words: Alkaloids, COVID-19, Docking study, FDA, Natural drugs.

\section{INTRODUCTION}

Coronavirus (COVID-19) is represented one of the main challenges affected the world population in now day and inflected melons of people over the world ${ }^{1,2}$. This pandemic is reflected the greatest hazardous epidemics that diseased and threatened all the human inhabitants at the end of 2019 and till now ${ }^{1,3-5}$. As a result of this pandemic infection at latent stages, is respiratory system disfunction and hypoxia. It was progressively spread to all territories of the world in spite of that it firstly distinguished in Wuhan, China ${ }^{4-7}$. According to World Health Organization classification, the COVID-19 is considered the greatest transmittable epidemic disaster which newly criticized the world populations, and the highest spreadable pandemic disease up till now ${ }^{8}$. Millions of peoples were infected with hirable pandemic crisis along with elevated death rate more than 1150000 death case $^{7}$. Regarding who reports, From the starting of that disaster, the number of affected people is constantly risen till the instant of article written. Since there is no approved and effective treatments for this epidemic crisis yet, utmost of the drug discovers and scientists, have engrossed their exertions to reach and discover an auspicious treatment, either by repurpose drugs, synthesis, semisynthesis, and natural occurring drugs which are predictable to own a optimistic effect on such epidemic type $e^{9,10}$. Alkaloids are naturally occurring organic nitrogenous compounds and can be detected in certain plant families ${ }^{11,12}$. It has been reputed for their medicinal values either as FDA approved drugs or in folk medicine ${ }^{11}$. They have been used as anti-inflammatory, analgesics, stimulant, antimicrobial, anticancer, antifungal, antispasmodics, neuropharmacologic and others ${ }^{13-15}$ Certain alkaloid individuals have been selected for theoretically testing their potentiality as antiviral drugs against the newly spread COVID-19 $9^{12,14}$. The selected alkaloidal members are FDA approved and possess safe and therapeutic uses at certain and calculated doses ${ }^{16}$. The two enzymes transcriptase and protease are vital key factors for reproduction and existence of RNA virus in host cell. COVID-19 is RNA virus type as a consequence, protease enzyme signifies as an one of most important targets for discovering of new antiviral drugs ${ }^{17}$. So, insight, in silico, or virtual docking studies aiming protease proteins of COVID-19, is considered as a new entry for discovering or repurposing new inhibitory drugs for COVID-1917-21. In this study, FDA safe alkaloids drugs were selected for research using docking program and the study were applied at five positions of protease targeting different proteins ${ }^{22,23}$. The main objectives of this virtual studies are discovering natural safe, and effective within short time which is essential factor in this epidemic crisis and to validate the affinity and binding types for the selected drugs with protease proteins.

\section{MATERIAL AND METHOD}

Molecular modeling was employed as a valuable technique for estimating the interaction of 
medication-receptor macromolecule. This software aids to increase the achievement rate of an experiment and reduces the experimental fees. Through the molecular docking analysis, the possible binding presence of drugs can be estimated on the active sites of the objective enzyme. Molecular docking has been done to show some naturally FDAapproved biologically active alkaloids with the SARS-CoV2 protease in our research. The PDB has been downloaded with the isolated crystal structures of protease enzymes active sites (5R7Y, 5R7Z, 5R80, 5R81 and 5R82). Virtual studies have been carried out using the London $\mathrm{dG}$ force and the results have been sophisticated with the application of force field energy. The 3D structure built up by the MOE program was developed for the production of natural medication, colchicine, codeine, piperine, papaverine, ergotamine, theophylline, theobromine, and caffeine for the study (Molecular Operating Environment, Version 2008.06, Chemical Computing Group Inc., QC, Canada). Described techniques were employed before docking which incorporate, running conformational analysis using systemic search, 3D protonation of the structures, applying the same docking protocol was used with ligands and selecting the least energetic conformer (Figure 1-5). Alkaloids docking experiments, have been used. Interactions, arene cation, and hydrogen connection with amino acid, have been summarized in (Tables 1-5).

\section{RESULTS AND DISCUSSION}

Five proteins of protease were used and downloaded from PDB in this analysis. The five-crystal structures (5R7Y, 5R7Z, 5R80, 5R81 and $5 \mathrm{R} 82$ ) were modified for the docking analysis. These five proteins play an important role in the construction, configuration, and conformation of protease enzymes. Some safe natural alkaloids FDA approved drugs have been used in docking studies. The five proteins were used to confirm their activity, to prove binding modes and to predict the SAR of the tested compounds. The docking energy score(s) for the compounds tested ranged from -2.9516 to $-24.7449 \mathrm{kcal} / \mathrm{mol}$. (Tables 1-5). Various drug-protein interactions have been observed, ranging from one to five interactions, including $\mathrm{H}$-bond acceptor, $\mathrm{H}$-bond donor, and arene cation interactions (Tables 1-5, Figures 1-5).

\section{Binding interactions of alkaloid with 5R7Y}

The docking scores of tested alkaloids with 5R7Y ranged from -19.2769 for papaverine and -4.8801 for colchicine. Gln 189 amino acid formed $\mathrm{H}$ bond acceptor with $\mathrm{C}=\mathrm{O}$ colchicine, with methoxy group, and furan oxygen of codeine, $\mathrm{N}$-atom and methoxy group of papaverine, while formed $\mathrm{H}$ bond donor alcoholic $\mathrm{OH}$ of codeine, amidic $\mathrm{N}$ and alcoholic $\mathrm{OH}$ of ergotamine. Arene cation interactions were observed between

Table 1: Interactions and docking score of alkaloids with 5R7Y.

\begin{tabular}{|c|c|c|c|c|c|c|}
\hline No. & Drug Name & Docking score & Number of interactions & Type of interaction & Amino acid & Function group \\
\hline \multirow[t]{14}{*}{1} & Colchicine & -4.8801 & 3 & Arene cation & His 41 & Phenyl ring \\
\hline & & & & H bond acceptor & Thr 25 & Methoxy of heptene \\
\hline & & & & $\mathrm{H}$ bond acceptor & Gln 189 & $\mathrm{C}=\mathrm{O}$ of amide \\
\hline & Codeine & -11.0815 & 3 & $\mathrm{H}$ bond acceptor & Gln 189 & Methoxy phenyl \\
\hline & & & & $\mathrm{H}$ bond acceptor & Gln 189 & O of furan \\
\hline & & & & $\mathrm{H}$ bond donor & Gln 189 & $\mathrm{OH}$ alcohol \\
\hline & Piperine & -13.1326 & 1 & $\mathrm{H}$ bond acceptor & Asn 142 & $\mathrm{C}=\mathrm{O}$ \\
\hline & Papaverine & -19.2769 & 2 & H bond acceptor & Gln 189 & $\mathrm{~N}$ atom \\
\hline & & & & $\mathrm{H}$ bond acceptor & Glu 166 & 4-methoxyphenyl \\
\hline & Ergotamine & -18.0130 & 2 & $\mathrm{H}$ bond donor & Gln 189 & $\mathrm{~N}$ of amide \\
\hline & & & & $\mathrm{H}$ bond donor & Gln 189 & $\mathrm{OH}$ of alcohol \\
\hline & Theophylline & -9.5423 & 1 & Arene cation & His 41 & Imidazole ring \\
\hline & Theobromine & -8.6920 & 1 & Arene cation & His 41 & Imidazole ring \\
\hline & Caffeine & -13.4502 & 1 & $\mathrm{H}$ bond acceptor & Glu 166 & $4-\mathrm{C}=\mathrm{O}$ \\
\hline
\end{tabular}

Table 2: Interactions and docking score of alkaloids with $\mathbf{5 R 7 Z . ~}$

\begin{tabular}{|c|c|c|c|c|c|c|}
\hline No. & Drug Name & Docking score & $\begin{array}{l}\text { Number of } \\
\text { interactions }\end{array}$ & Types of interaction & Amino acids & Function group \\
\hline \multirow{2}{*}{1} & \multirow{2}{*}{ colchicine } & \multirow{2}{*}{-22.1963} & \multirow{2}{*}{2} & $\mathrm{H}$ bond acceptor & His 163 & $\mathrm{C}=\mathrm{O}$ of amide \\
\hline & & & & $\mathrm{H}$ bond acceptor & Gln 189 & Methoxy of heptene \\
\hline \multirow{2}{*}{2} & \multirow{2}{*}{ Codeine } & \multirow{2}{*}{-17.4083} & \multirow{2}{*}{2} & $\mathrm{H}$ bond acceptor & Gly 143 & Methoxy phenyl \\
\hline & & & & $\mathrm{H}$ bond acceptor & His 163 & $\mathrm{OH}$ alcohol \\
\hline \multirow[t]{2}{*}{3} & \multirow[t]{2}{*}{ Piperine } & \multirow[t]{2}{*}{-17.2722} & \multirow[t]{2}{*}{1} & Arene cation & His 41 & Phenyl ring \\
\hline & & & & $\mathrm{H}$ bond acceptor & Gln 189 & 7-methoxyisoquinoline \\
\hline \multirow[t]{2}{*}{4} & \multirow[t]{2}{*}{ Papaverine } & \multirow[t]{2}{*}{-23.1619} & \multirow[t]{2}{*}{3} & $\mathrm{H}$ bond acceptor & Gly 143 & 4imethoxyphenyl \\
\hline & & & & Arene cation & His 41 & Phenyl ring \\
\hline \multirow{2}{*}{5} & \multirow{2}{*}{ Ergotamine } & \multirow{2}{*}{-19.2085} & \multirow{2}{*}{2} & $\mathrm{H}$ bond acceptor & Asn 142 & $\mathrm{C}=\mathrm{O}$ of amide \\
\hline & & & & H bond donor & Glu 166 & OH alcohol \\
\hline 6 & Theophylline & -7.4275 & 1 & $\mathrm{H}$ bond donor & Glu 166 & $9-\mathrm{N}$ \\
\hline \multirow{2}{*}{7} & \multirow{2}{*}{ Theobromine } & \multirow{2}{*}{-7.7700} & \multirow{2}{*}{2} & $\mathrm{H}$ bond acceptor & Glu 166 & $4-\mathrm{C}=\mathrm{O}$ \\
\hline & & & & H bond donor & Glu 166 & $3-\mathrm{N}$ \\
\hline 8 & caffeine & -11.5933 & 1 & Arene cation & His 41 & Imidazole ring \\
\hline
\end{tabular}


Table 3: Interactions and docking score of alkaloids with 5 R80

\begin{tabular}{|c|c|c|c|c|c|c|}
\hline & Drug Name & Docking score & Number of interactions & Interaction types & Amino acid & Function group \\
\hline \multirow{2}{*}{1} & \multirow{2}{*}{ Colchicine } & \multirow{2}{*}{-12.1316} & \multirow{2}{*}{ ( } & $\mathrm{H}$ bond donor & Glu 166 & $\mathrm{~N}$ of amide \\
\hline & & & & $\mathrm{H}$ bond acceptor & Gln 189 & $\mathrm{C}=\mathrm{O}$ of amide \\
\hline 2 & codeine & -7.4168 & 1 & H bond donor & Glu 166 & $\mathrm{OH}$ of alcoholic group \\
\hline 3 & Piperine & -16.6878 & 1 & $\mathrm{H}$ bond acceptor & Gln 189 & $\mathrm{C}=\mathrm{O}$ \\
\hline \multirow[t]{2}{*}{4} & \multirow[t]{2}{*}{ Papaverine } & \multirow[t]{2}{*}{-16.7969} & \multirow[t]{2}{*}{2} & $\begin{array}{l}\text { Arene cation } \\
\text { interaction }\end{array}$ & His 41 & Phenyl of sioquinoline \\
\hline & & & & $\mathrm{H}$ bond acceptor & Gln 189 & 3-methoxy \\
\hline \multirow{2}{*}{5} & \multirow{2}{*}{ Ergotamine } & \multirow{2}{*}{-24.7449} & \multirow{2}{*}{2} & $\mathrm{H}$ bond donor & Glu 166 & $\mathrm{~N}$ of amide \\
\hline & & & & $\mathrm{H}$ bond acceptor & Glu 166 & $\mathrm{C}=\mathrm{O}$ of oxazole \\
\hline \multirow{2}{*}{6} & \multirow{2}{*}{ Theophylline } & \multirow{2}{*}{-6.0634} & \multirow{2}{*}{2} & $\mathrm{H}$ bond acceptor & Gln 189 & $2-\mathrm{C}=\mathrm{O}$ \\
\hline & & & & $\mathrm{H}$ bond donor & Glu 166 & $9-\mathrm{N}$ \\
\hline 7 & Theobromine & -9.3451 & 1 & $\mathrm{H}$ bond acceptor & Gln 189 & $2-\mathrm{C}=\mathrm{O}$ \\
\hline 8 & Caffeine & -11.9342 & 1 & $\mathrm{H}$ bond acceptor & Gln 189 & $2-\mathrm{C}=\mathrm{O}$ \\
\hline
\end{tabular}

Table 4: Interactions and docking score of alkaloids with $\mathbf{5 R 8 1 .}$

\begin{tabular}{|c|c|c|c|c|c|c|}
\hline No. & Drug Name & Docking score & Number of interaction & Types of interaction & Amine & Function group \\
\hline \multirow{3}{*}{1} & \multirow{3}{*}{ Colchicine } & \multirow{3}{*}{-15.1191} & \multirow{3}{*}{3} & Arene action interaction & His 41 & Phenyl ring \\
\hline & & & & $\mathrm{H}$ bond acceptor & Gly 143 & Carbamide $\mathrm{C}=\mathrm{O}$ group \\
\hline & & & & $\mathrm{H}$ bond acceptor & Gln 189 & $\mathrm{C}=\mathrm{O}$, of cycloheptene \\
\hline \multirow{2}{*}{2} & \multirow{2}{*}{ Codeine } & \multirow{2}{*}{-16.9709} & \multirow{2}{*}{2} & $\mathrm{H}$ bond donor & Asn 142 & Alcoholic $\mathrm{OH}$ \\
\hline & & & & $\mathrm{H}$ bond acceptor & Gln 189 & O of furan \\
\hline 3 & Piperine & -16.7741 & 1 & $\mathrm{H}$ bond acceptor & Gly 143 & $\mathrm{C}=\mathrm{O}$ \\
\hline \multirow[t]{2}{*}{4} & \multirow[t]{2}{*}{ Papaverine } & \multirow[t]{2}{*}{-18.5474} & \multirow[t]{2}{*}{2} & $\mathrm{H}$ bond acceptor & Gly 143 & $\begin{array}{l}\text { O of 4-methoy of dime- } \\
\text { thoxy phenyl }\end{array}$ \\
\hline & & & & $\mathrm{H}$ bond acceptor & Gln 189 & 6-methoxy of isoquinoline \\
\hline \multirow{5}{*}{5} & \multirow{5}{*}{ Ergotamine } & \multirow{5}{*}{-20.4813} & \multirow{5}{*}{5} & H-bond donor & His 41 & $\mathrm{~N}$ of pyrrole \\
\hline & & & & Arene cation interaction & His 41 & Pyrrole ring \\
\hline & & & & $\mathrm{H}$ bond acceptor & Gln 189 & $\mathrm{C}=\mathrm{O}$ of amide \\
\hline & & & & H-bond accptor & Gln 189 & $\mathrm{C}=\mathrm{O}$ of oxazole ring \\
\hline & & & & $\mathrm{H}$ bond donor & Glu 166 & Alcoholic $\mathrm{OH}$ \\
\hline 6 & Theophylline & -9.6485 & 1 & $\mathrm{H}$ bond acceptor & Gln 189 & $4-\mathrm{C}=\mathrm{O}$ \\
\hline \multirow{2}{*}{7} & \multirow{2}{*}{ Theobromine } & \multirow{2}{*}{-9.2269} & \multirow{2}{*}{2} & $\mathrm{H}$ bond acceptor & Gly 143 & $2-\mathrm{C}=\mathrm{O}$ \\
\hline & & & & $\mathrm{H}$ bond acceptor & Glu 166 & $7-\mathrm{N}$ \\
\hline \multirow{2}{*}{8} & \multirow{2}{*}{ Caffeine } & \multirow{2}{*}{-11.8040} & \multirow{2}{*}{2} & H-bond acceptor & Gly 143 & $2-\mathrm{C}=\mathrm{O}$ \\
\hline & & & & H-bond acceptor & Glu 166 & $7 \mathrm{~N}$ \\
\hline
\end{tabular}

Table 5: Interactions and docking score of alkaloids with $\mathbf{5 R 8 2 .}$

\begin{tabular}{|c|c|c|c|c|c|c|}
\hline No & compound & Docking score & Number of bonds & Type of interactions & Amino acids & Function group \\
\hline \multirow{2}{*}{1} & \multirow{2}{*}{ Colchicine } & \multirow{2}{*}{-2.9516} & \multirow{2}{*}{2} & $\mathrm{H}$ bond donor & Gln 189 & $\mathrm{~N}$ of amide \\
\hline & & & & H Bond acceptor & Glu 166 & $\mathrm{C}=\mathrm{O}$ of heptene \\
\hline 2 & Codeine & -14.0087 & 1 & H Bond acceptor & Glu 166 & $\mathrm{OH}$ of alcohol \\
\hline \multirow{2}{*}{3} & \multirow{2}{*}{ Piperine } & \multirow{2}{*}{-13.9889} & \multirow{2}{*}{2} & $\mathrm{H}$ bond acceptor & Thr 25 & O of dioxalane \\
\hline & & & & $\mathrm{H}$ bond acceptor & Glu 166 & $\mathrm{C}=\mathrm{O}$ \\
\hline \multirow{3}{*}{4} & \multirow{3}{*}{ Papaverine } & \multirow{3}{*}{-14.1058} & \multirow{3}{*}{3} & $\mathrm{H}$ bond acceptor & Gly 143 & 6-methoxy \\
\hline & & & & $\mathrm{H}$ bond acceptor & Gly 143 & 7-methoxy \\
\hline & & & & Arene cation interaction & His 41 & $\begin{array}{l}\text { Phenyl ring of } \\
\text { isoquinoline }\end{array}$ \\
\hline \multirow{2}{*}{5} & \multirow{2}{*}{ Ergotamine } & \multirow{2}{*}{-4.7900} & \multirow{2}{*}{2} & $\mathrm{H}$ bond donor & Asn 142 & $\mathrm{~N}$ of amide \\
\hline & & & & $\mathrm{H}$ bond donor & Gln 189 & $\mathrm{OH}$ of alcohol \\
\hline \multirow{3}{*}{6} & \multirow{3}{*}{ Theophylline } & \multirow{3}{*}{-9.0847} & \multirow{3}{*}{3} & $\mathrm{H}$ bond acceptor & Gly 143 & $7-\mathrm{N}$ \\
\hline & & & & $\mathrm{H}$ bond acceptor & Glu 166 & $4-\mathrm{C}=\mathrm{O}$ \\
\hline & & & & Arene cation & His 41 & Imidazole ring \\
\hline \multirow[b]{2}{*}{7} & \multirow[b]{2}{*}{ Theobromine } & \multirow[b]{2}{*}{-14.2779} & \multirow[b]{2}{*}{2} & $\mathrm{H}$ bond acceptor & Gly 143 & $7-\mathrm{N}$ \\
\hline & & & & Arene cation & His 41 & Imidazole ring \\
\hline \multirow{2}{*}{8} & \multirow{2}{*}{ Caffeine } & \multirow{2}{*}{-11.8904} & \multirow{2}{*}{2} & $\mathrm{H}$ bond acceptor & Glu 166 & $4-\mathrm{C}=\mathrm{O}$ \\
\hline & & & & Arene cation & His 41 & Imidazole ring \\
\hline
\end{tabular}




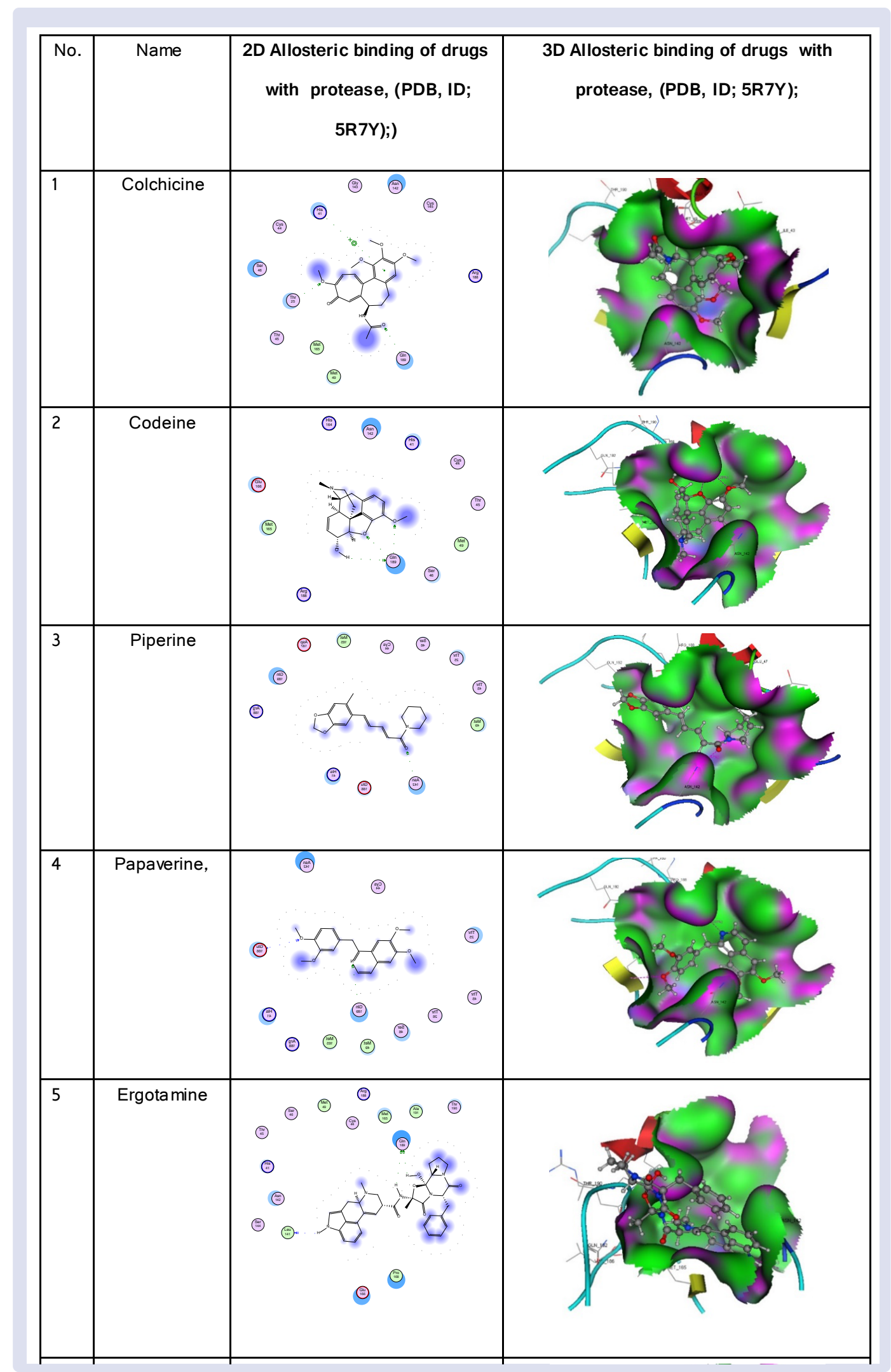




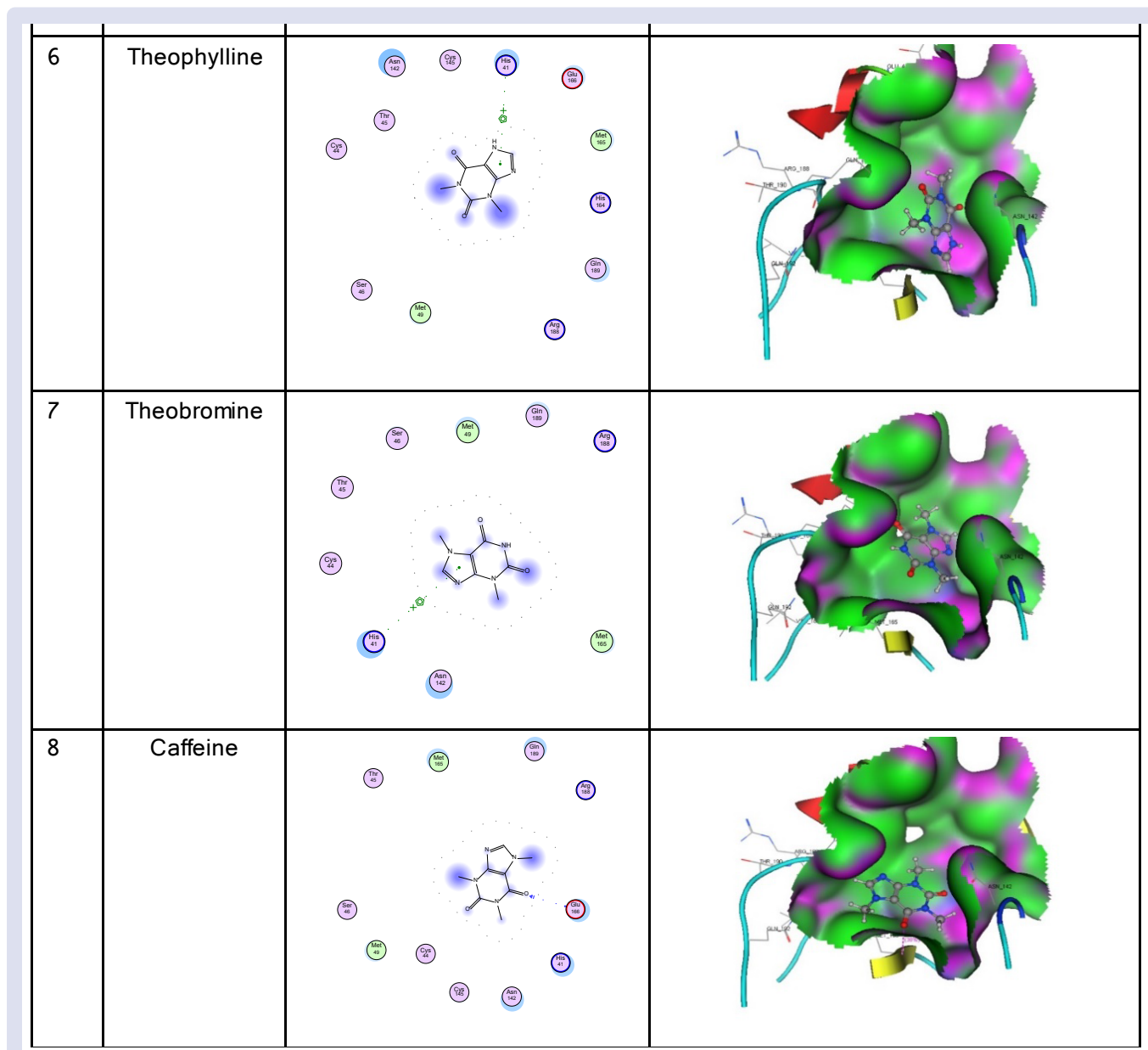

Figure 1:2D Allosteric binding of drugs with protease, (PDB, ID; 5R7Y); 3D Allosteric binding of drugs with protease, (PDB, ID; 5R7Y).

amino acid his 41 with phenyl ring of colchicine, and imidazole of both theophylline and theobromine. colchicine and codeine had 3 interactions with 5R7Y, but the other alkaloids had only one or two interactions (Figure 1, Table 1).

\section{Binding interactions of alkaloid with $5 R 7 Z$}

The docking scores of tested alkaloids with 5R7Z ranged from -23.1619 for papaverine and -7.4275 for theophylline. Glu 166 amino acid formed $\mathrm{H}$ bond acceptor with $\mathrm{C}=\mathrm{O}$ of theobromine, while formed $\mathrm{H}$ bond donor with alcoholic $\mathrm{OH}$ of ergotamine, $\mathrm{N}$ of theophylline and theobromine. Gln 189 constricted H-bond acceptor with methoxy groups of colchicine and papaverine. Arene cation interactions were observed between amino acid his 41 with phenyl rings of piperine and papaverine and imidazole of caffeine (Figure 2, Table 2).

\section{Binding interactions of alkaloid with 5R80}

The number of interactions of alkaloids with 5 R80 are 2 (colchicine, papaverine, ergotamine and theophylline) but codeine, piperine, theobromine and caffeine formed only one interaction. The docking scores of tested alkaloids with 5R80 ranged from -24.7449 for ergotamine and -6.0634 for theophylline. Glu 166 amino acid formed $\mathrm{H}$ bond donor with amidic $\mathrm{N}$ of colchicine and ergotamine, alcoholic $\mathrm{OH}$ of codeine, and $\mathrm{N}$ atom of theophylline while formed $\mathrm{H}$ bond donor with $\mathrm{C}=\mathrm{O}$ of ergotamine, Gln 189 made $\mathrm{H}$-bond acceptor with $\mathrm{C}=\mathrm{O}$ groups of colchicine, piperine, theophylline, theobromine and caffeine but with methoxy group of papaverine (Figure 3, Table 3).

\section{Binding interactions of alkaloid with 5R81}

The docking scores of tested alkaloids with 5R81 ranged from -20.4813 for ergotamine and -9.2269 for theobromine. Gly 143 amino acid formed five $\mathrm{H}$ bond acceptor, with $\mathrm{C}=\mathrm{O}$ groups of colchicine, piperine, caffeine and theobromine while with methoxy group of papaverine. Gln 189 made six $\mathrm{H}$ bonds acceptor with $\mathrm{C}=\mathrm{O}$ groups of colchicine, ergometrine (amidic and oxazole $\mathrm{C}=\mathrm{O}$ ), and theophylline but with furan of codeine, and methoxy of papaverine (Figure 4, Table 4).

\section{Binding interactions of alkaloid with 5R82}

The docking scores of tested alkaloids with 5R82 ranged from -14.2779 for theobromine and -2.9516 for colchicine. Papaverine formed three interactions, two $\mathrm{H}$ bond acceptor with gly 143 and one arene cation interaction with his 41 . Also, theophylline formed three interactions, one is arene cation interaction with his 41 and two $\mathrm{H}$ bond acceptor with gly 143 and glu166 amino acids (Figure 5, Table 5). 


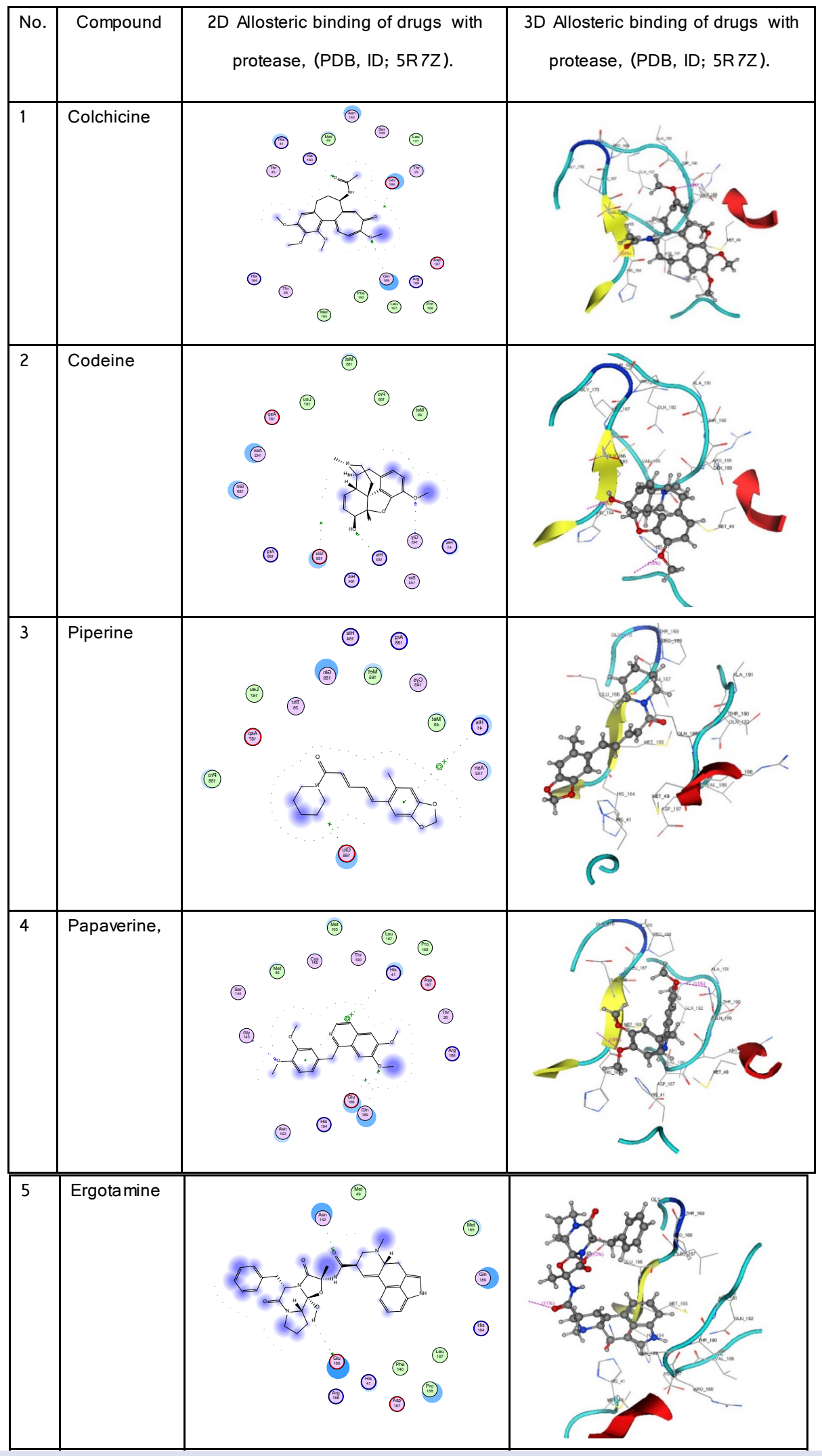




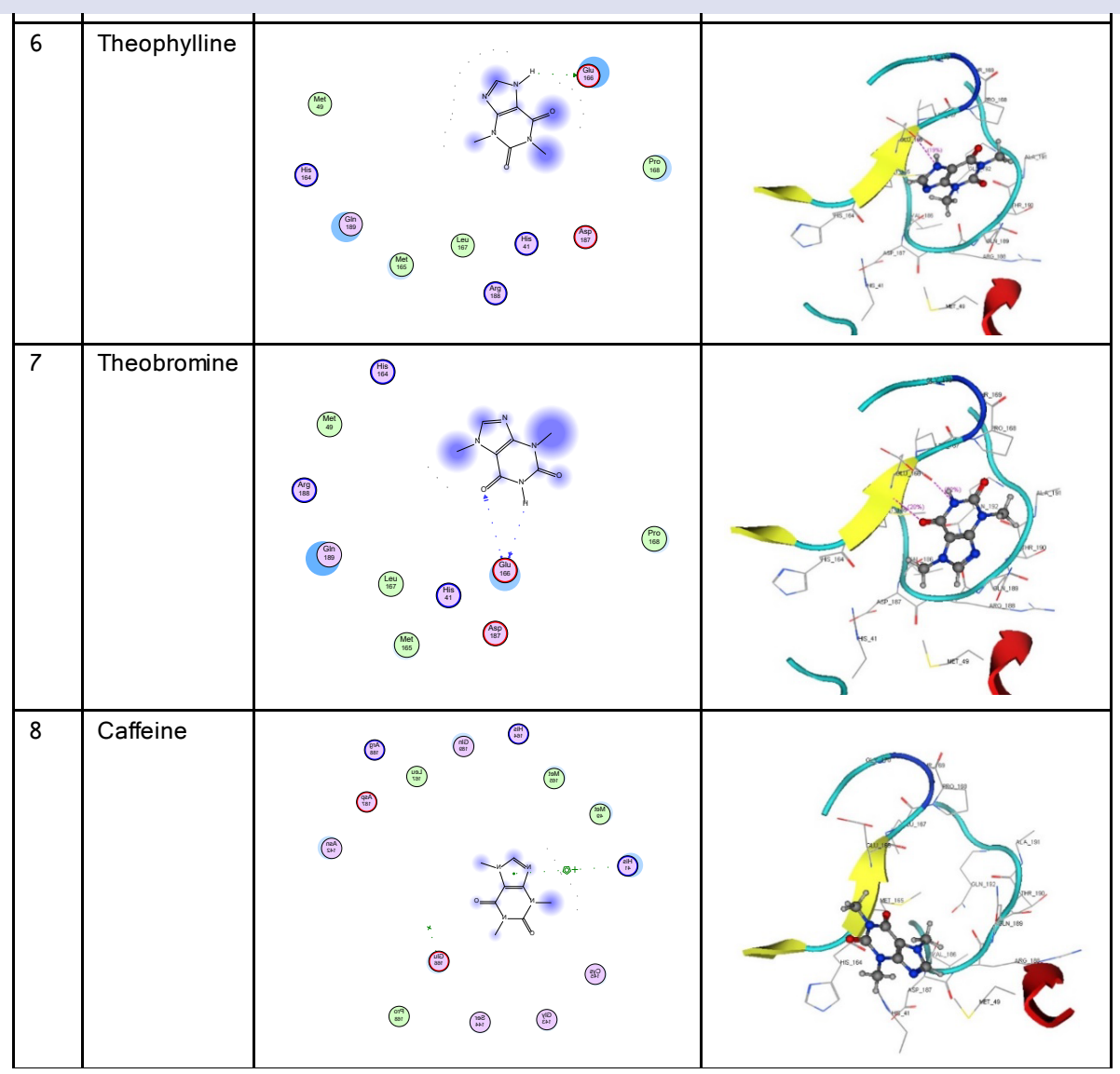

Figure 2: 2D Allosteric binding of drugs with protease, (PDB, ID; 5R7Z); 3D Allosteric binding of drugs with protease, (PDB, ID; 5R7Z).

\begin{tabular}{|c|c|c|c|}
\hline No. & $\begin{array}{l}\text { Compound } \\
\text { name }\end{array}$ & $\begin{array}{l}\text { 2D Allosteric binding of drugs with } \\
\text { protease, (PDB, ID; 5R80) }\end{array}$ & $\begin{array}{l}\text { 3D Allosteric binding of drugs with } \\
\text { protease, (PDB, ID; 5R80) }\end{array}$ \\
\hline 1 & Colch icine & 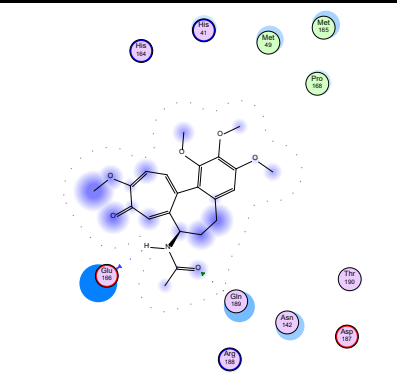 & \\
\hline 2 & Codeine & 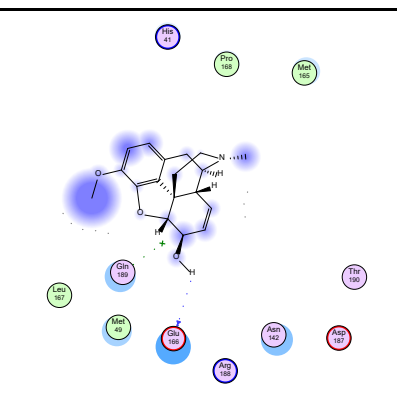 & \\
\hline
\end{tabular}




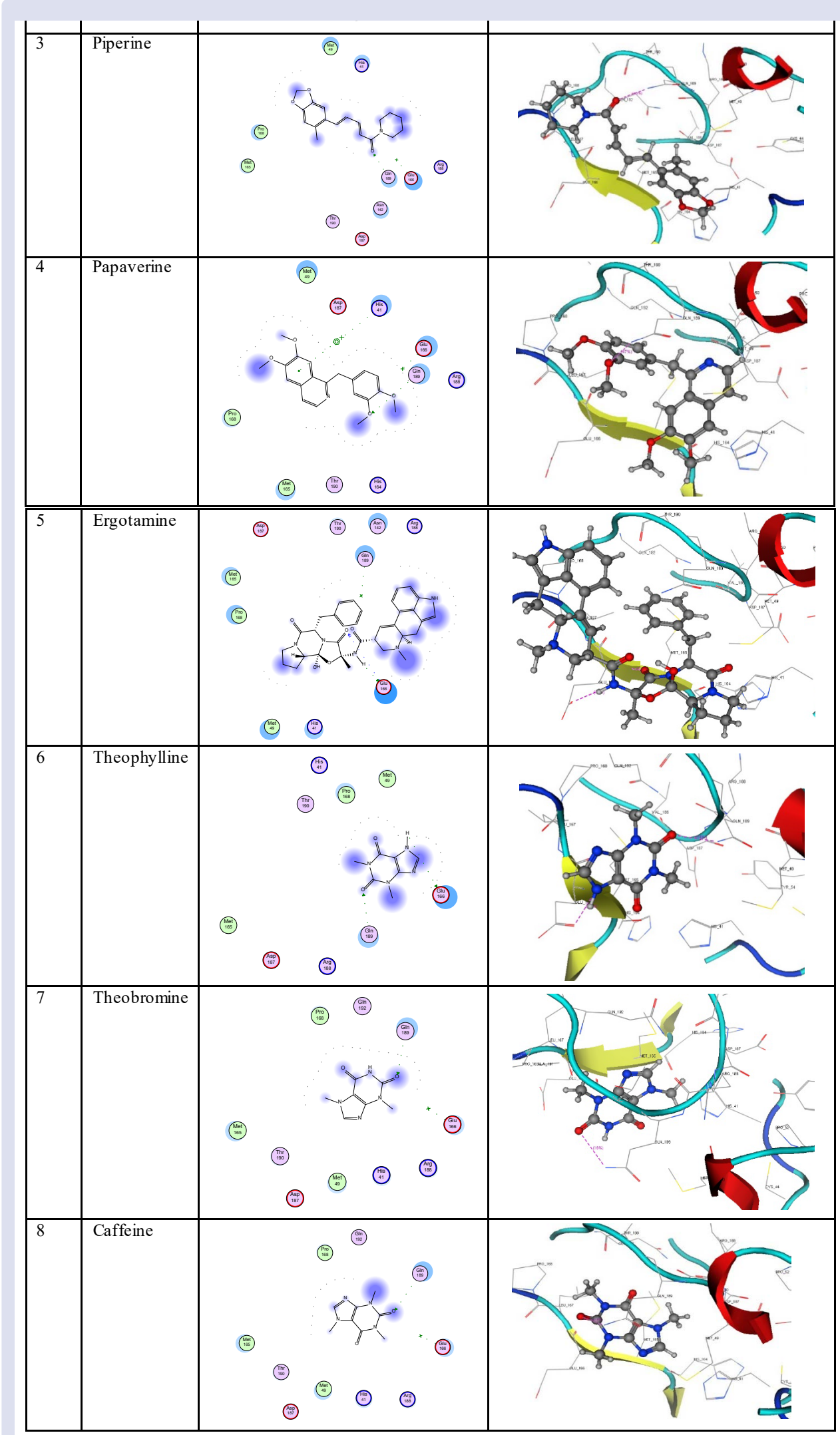

Figure 3: 2D Allosteric binding of drugs with protease, (PDB, ID; 5R80); 3D Allosteric binding of drugs with protease, (PDB, ID; 5R80). 


\begin{tabular}{|c|c|c|c|}
\hline \begin{tabular}{|l} 
No. \\
\end{tabular} & Name & $\begin{array}{l}\text { 2D Allosteric binding of drugs with } \\
\text { protease, (PDB, ID; 5R81) }\end{array}$ & $\begin{array}{l}\text { 3D Allosteric binding of drugs with } \\
\text { protease, (PDB, ID; 5R } 81 \text { ) }\end{array}$ \\
\hline \begin{tabular}{|l|}
1 \\
\end{tabular} & Colch icine & 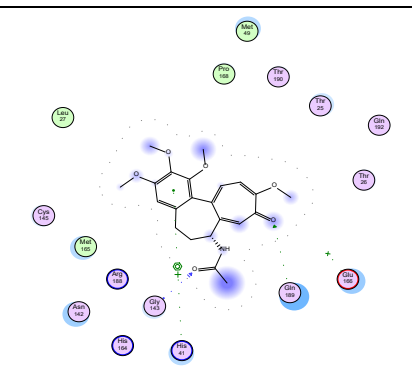 & V \\
\hline 2 & Codeine & 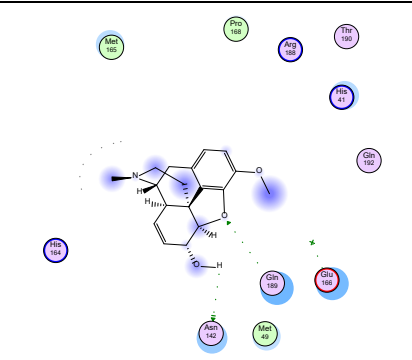 & \\
\hline 3 & Piperine & 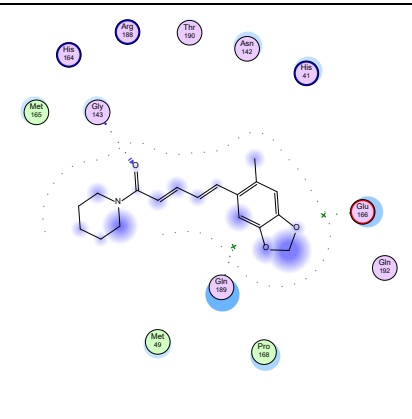 & 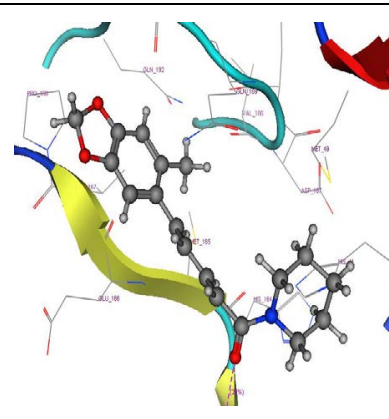 \\
\hline 4 & Papaverine, & 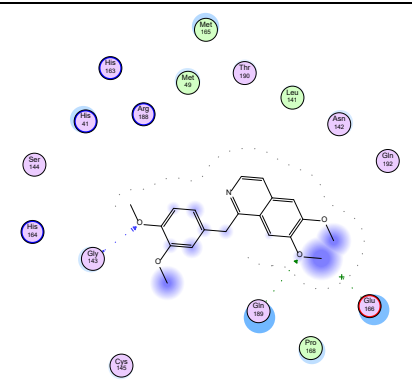 & \\
\hline 5 & Ergotamine & $0^{+\infty}+\infty$ & \\
\hline
\end{tabular}




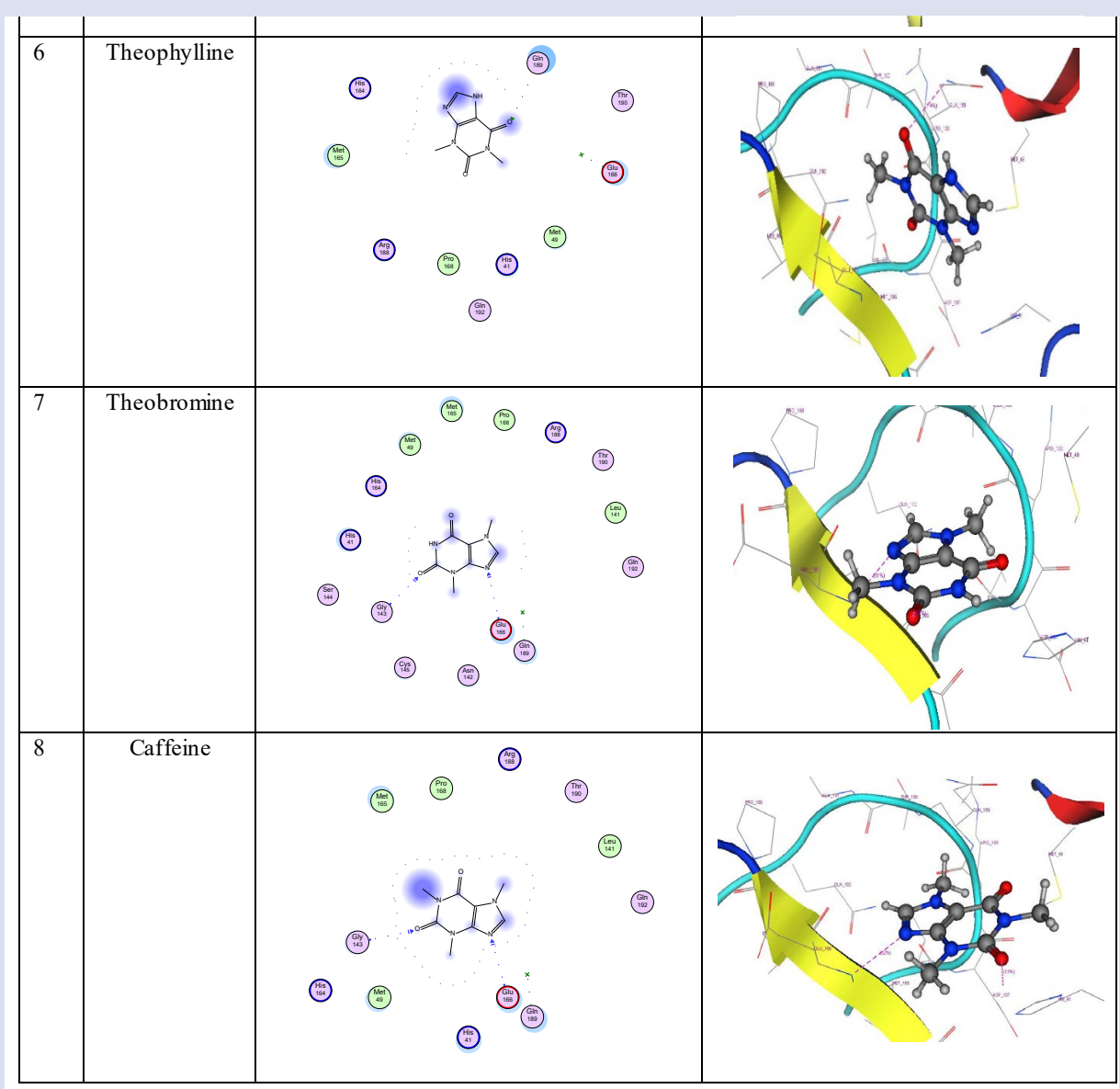

Figure 4: 2D Allosteric binding of selected alkaloids with protease, (PDB, ID; 5R81); 3D Allosteric binding of drugs with protease, (PDB, ID; 5R81).

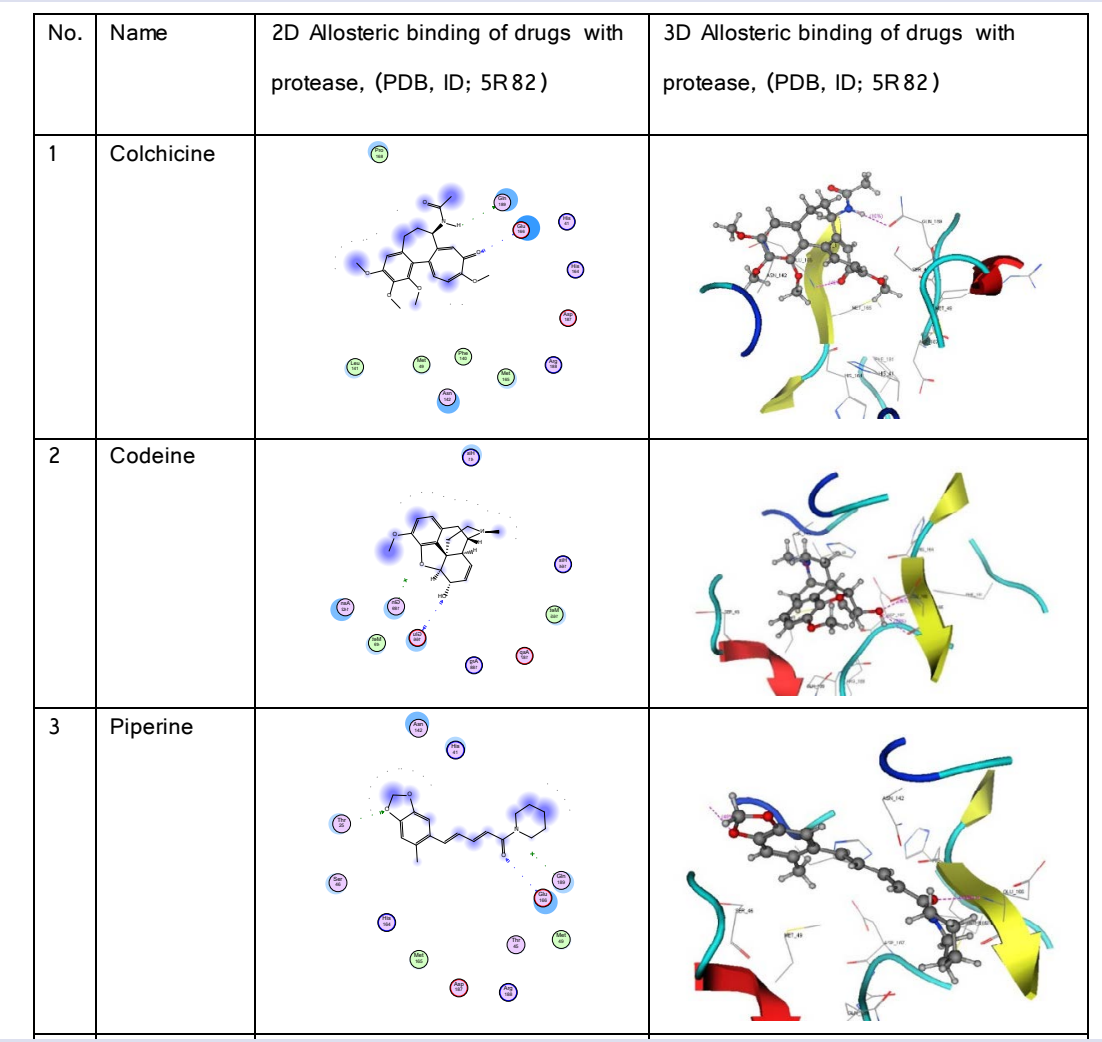




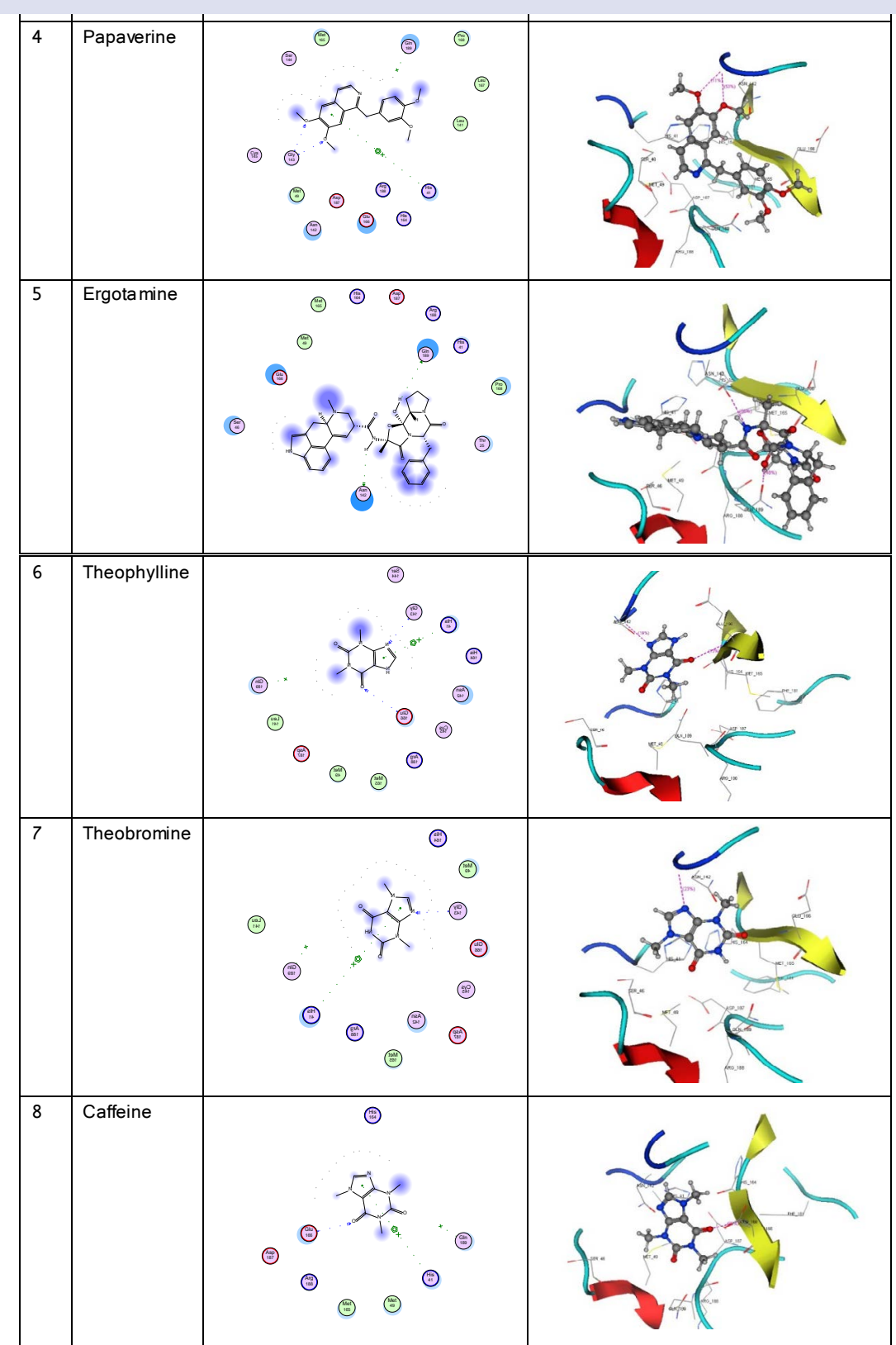

Figure 5:2D Allosteric binding of drugs with protease, (PDB, ID; 5R82); 3D Allosteric binding of drugs with protease, (PDB, ID; 5R82).

\section{CONCLUSION}

Gln 189 and his 41 amino acids represent a corner stone for binding of alkaloid with 5R7Y while papaverine has the highest docking score with $5 R 7 Z$ with three interactions. Ergotamine has the highest docking score with $5 \mathrm{R} 7 \mathrm{Z}$ with two H-bonds one acceptor and the another is donor. 5R81 amino acids, Gln 189 and Gly 143 formed six and five H-bond acceptors, respectively. While in 5R82, the amino acids Glu 166 formed five interactions with colchicine, codeine, piperine, theophylline and caffeine while his 41 formed arene cation interactions with papaverine, theophylline, theobromine and caffeine. Among the tested drugs, papaverine and ergometrine revealed high docking scores for all five proteins (score ranged from, -14.1058 to 23.1619 for papaverine and, -4.7900 to 24.7449 for ergometrine) and number of interactions with all tested proteins are two to three for papaverine but for ergometrine are two to five.

\section{REFERENCES}

1. Baildya N, Ghosh NN, Chattopadhyay AP. Inhibitory activity of hydroxychloroquine on COVID-19 main protease: An insight from MD-simulation studies. Journal of Molecular Structure. 2020:128595.

2. Calisher C, Carroll D, Colwell R. Statement in support of the scientists, public health professionals, and medical professionals of China combatting COVID-19. The Lancet. 2020;395:e42-3.

3. Kahn JS, Mclntosh K. History and recent advances in coronavirus discovery The Pediatric infectious disease journal. 2005;24:S223-7.

4. Li J, Zhou X, Zhang Y, et al. Crystal structure of SARS-CoV-2 main protease in complex with a Chinese herb inhibitor shikonin. bioRxiv. 2020.

5. Manach C, Scalbert A, Morand C, Rémésy C, Jiménez L. Polyphenols: food sources and bioavailability. The American journal of clinical nutrition. 2004;79:727-47.

6. Marinho EM, de Andrade Neto JB, Silva J. Virtual screening based on molecular docking of possible inhibitors of Covid-19 main protease. Microbial Pathogenesis. 2020:104365. 
7. Organization WH, organization Wh. Coronavirus disease (COVID-2019) situation reports 2020.

8. Rout J, Swain BC, Tripathy U. In Silico Investigation of Spice Molecules as Potent Inhibitor of SARS-CoV-2. 2020.

9. Shahidi F, Ambigaipalan P. Phenolics and polyphenolics in foods, beverages and spices: Antioxidant activity and health effects-A review. Journal of functional foods. 2015;18:820-97.

10. Yu J-w, Wang L, Bao L-d. Exploring the Active Compounds of Traditional Mongolian Medicine in Intervention of Novel Coronavirus (COVID-19) Based on Molecular Docking Method. Journal of Functional Foods. 2020:104016.

11. Manske RHF, Holmes HL. The alkaloids: chemistry and physiology: Elsevier; 2014.

12. Evans WC. Trease and evans' pharmacognosy E-book: Elsevier Health Sciences; 2009.

13. Hadi S, Bremner JB. Initial studies on alkaloids from Lombok medicinal plants. Molecules. 2001;6:117-29.

14. Babbar N. An introduction to alkaloids and their applications in pharmaceutical chemistry. The Pharma Innovation Journal. 2015;4:74-5.

15. Kurek J. Alkaloids: Their importance in Nature and Human life: BoD-Books on Demand; 2019

16. Roberts MF. Alkaloids: biochemistry, ecology, and medicinal applications: Springer Science \& Business Media; 2013.
17. Shereen MA, Khan S, Kazmi A, Bashir N, Siddique R. COVID-19 infection: Origin, transmission, and characteristics of human coronaviruses. Journal of Advanced Research. 2020.

18. Alkhaldi AA, Musa A, Mostafa EM, Amin E, De Koning HP. Docking Studies and Antiprotozoal Activity of Secondary Metabolites Isolated from Scrophularia syriaca Benth. Growing in Saudi Arabia. Records of Natural Products. 2020;14:30.

19. Abdelgawad MA, Bakr RB, Ahmad W, Al-Sanea MM, Elshemy HA. New pyrimidine-benzoxazole/benzimidazole hybrids: Synthesis, antioxidant, cytotoxic activity, in vitro cyclooxygenase and phospholipase A2-V inhibition. Bioorganic chemistry. 2019;92:103218.

20. Abdelgawad MA, Bakr RB, El-Gendy AO, Kamel GM, Azouz AA, Bukhari SNA Discovery of a COX-2 selective inhibitor hit with anti-inflammatory activity and gastric ulcer protective effect. Future Medicinal Chemistry. 2017;9:1899-912.

21. Abdelgawad MA, Belal A, Ahmed OM. Synthesis, molecular docking studies and cytotoxic screening of certain novel thiazolidinone derivatives substituted with benzothiazole or benzoxazole. Journal of Chemical and Pharmaceutical Research. 2013:5:318-27.

22. Shin MD, Shukla S, Chung YH, et al. COVID-19 vaccine development and a potential nanomaterial path forward. Nature nanotechnology. 2020;15:646-55.

23. Ghoneim MM, Musa A, El-Hela AA, Elokely KM. Evaluation and understanding the molecular basis of the antimethicillin-resistant Staphylococcus aureus activity of secondary metabolites isolated from Lamium amplexicaule. Pharmacognosy Magazine. 2018;14:3. 


\section{GRAPHICAL ABSTRACT}

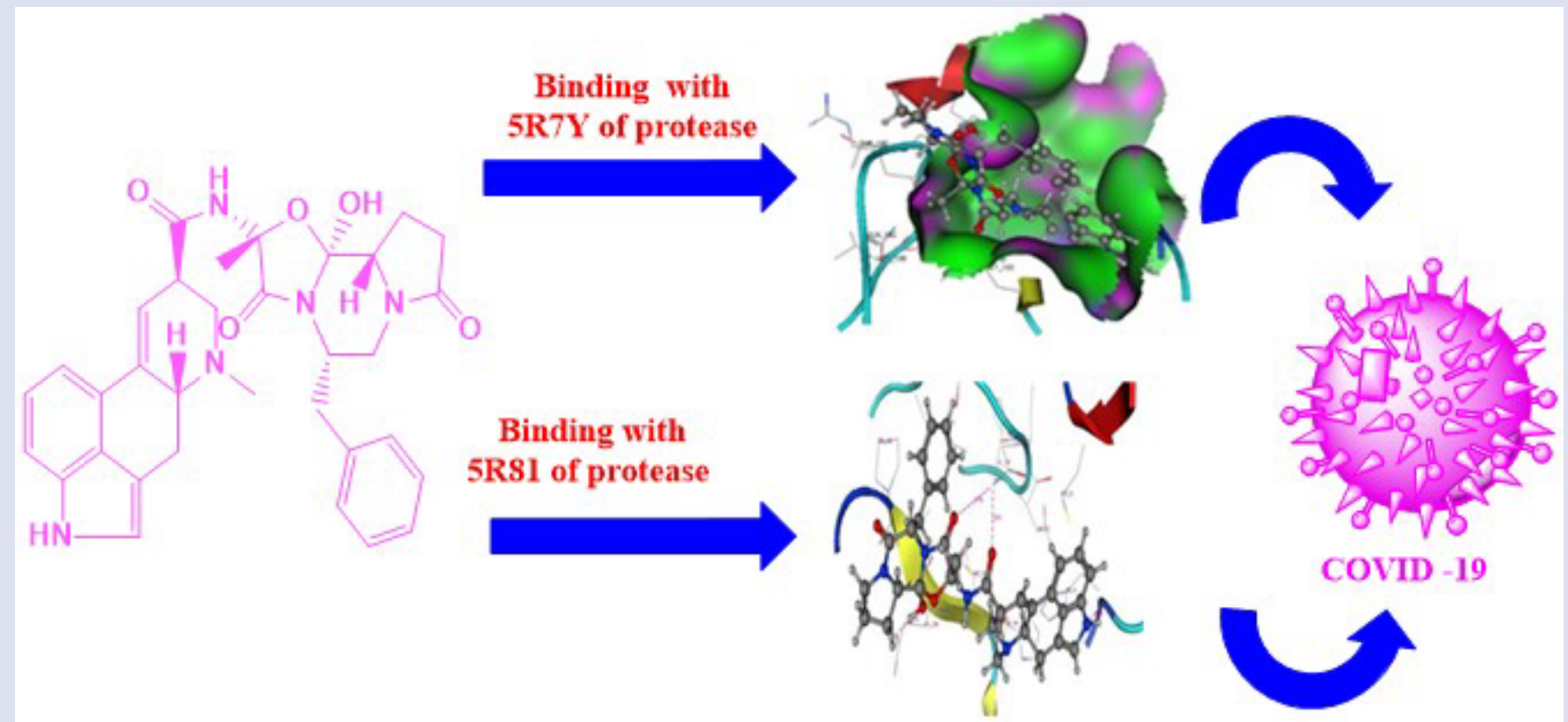

\section{ABOUT AUTHORS}

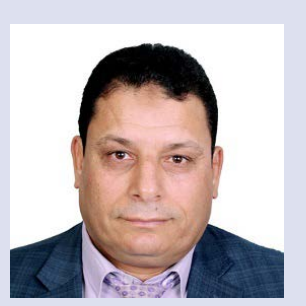

Prof. Dr. Ahmed El-Ghorab studied chemistry at Benha University and obtained his PhD in applied organic chemistry in 1999. He was appointed as a professor of flavor chemistry at NRC in 1990 -till now. He worked at California Davis University, Davis, CA, USA, in 2005 and as a visiting professor in UAF PK in 2009. Currently, he works as a professor of applied organic chemistry at Jouf University. He has authored 85 peer-reviewed publications in his field.

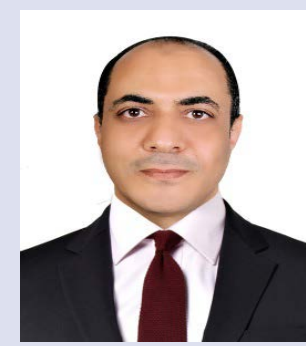

Dr. Arafa Musa is an assistant professor of Pharmaceutical Science. He is the Head of Pharmacognosy Department at College of Pharmacy, Jouf University, KSA. He awarded his Ph.D. in Pharmacognosy 2012 Through a visiting scholarship system between Al-Azhar University, Cairo, Egypt and LudwigMaximillian University (LMU), Munich, Germany (2007-2009). He has been involved in many collaborative research projects. His research interest is Drug Discovery from its Natural Sources, isolation of Natural Products, characterization, computational and mechanistic studies of active secondary metabolites.

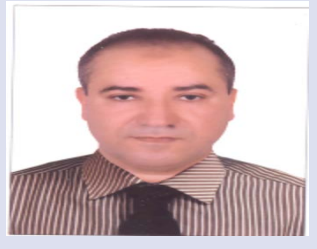

Mohamed A. Abdelgawad is a professor and supervisor of pharmaceutical chemistry department, college of pharmacy, Jouf university, Sakaka, Aljouf, KSA (till now). He was an academic supervisor of clinical pharmacy program at Faculty of Pharmacy, Egypt (2011-14). He was assistant professor in pharmaceutical organic chemistry, faculty of pharmacy, Egypt (2008-13). He is an examiner for PhD and master's degree in pharmaceutical chemistry. He was supervisor for three PhD thesis and ten master thesis. He has 60 publication at international journals, and he is reviewer for several medicinal chemistry journals also he is an editor for international journals.

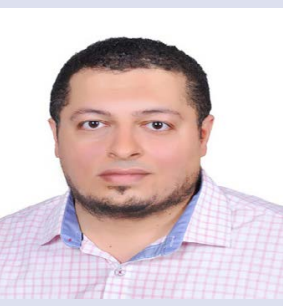

Mohammed Gamal is head of quality unit and an assistant professor, medicinal chemistry department, pharmacy college, Jouf university KSA. Gamal completed his PhD in June 2013 in pharmaceutical analytical chemistry ( analysis of some drugs acting on GIT). In 2011 he joined Charles sturt university, Wagga Wagga ,Australia biomedical school polyphenol analysis group in a scholarship. His PhD thesis was chosen as the best Ph. D. thesis in Beni Suef university in 2014. Currently, Gamal has about 34 publications, 104 citations with 6 h-index in Google scholar. Gamal reviewed 224 papers according to publons website. 

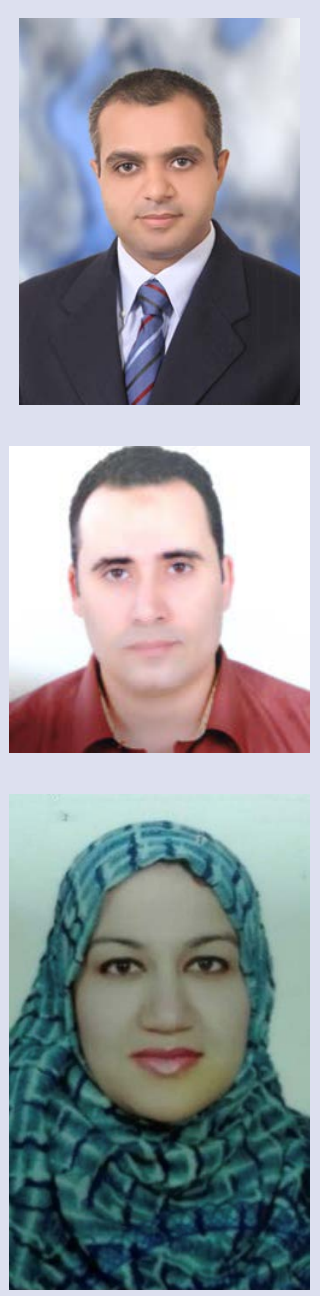

Dr. Ehab Mohamed Mostafa was born on 1973. He has graduated from the faculty of pharmacy, AlAzhar University, Cairo, Egypt (B.Sc, 1996). He earned his master degree in natural products chemistry (2002). From 2006- 2008 worked as Ph. D. Candidate in the Institute for Pharmaceutical Biology and Biotechnology, Heinrich Heine University, Düsseldorf, Germany. He received his Ph. D in 2009.

Dr. Mohammed Ghoneim is an assistant professor of Pharmaceutical Science. He is the Head of Clinical Pharmacy Department and Director of Pharm. D program, College of Pharmacy, Al-Maarefa University. He received his Ph.D. in Pharmaceutical Science in 2014 Through a visiting scholarship system between the University of Al-Azhar,Cairo, Egypt and University of Mississippi and National Center for Natural Products Resaerch, MS 38677, USA (2009-2014). He has been involved in many collaborative research projects. His research interest is Natural Products, isolation, characterization, computational and mechanistic studies of active secondary metabolites against MRSA, also other infectious diseases and anticancer metabolites.

Dr. Shaimaa Salah EIDeen Hussein was born on 1983. She has graduated from the faculty of pharmacy, Cairo University, Cairo, Egypt (B.Sc., 2004). She earned her master degree in Pharmacology \& Toxicology (2013). From 2013 - 2015, she worked in Medical Studies \& Research Center, Cairo, Egypt. She received her Ph.D. in 2016.

Cite this article: Mostafa EM, Gamal M, Ghoneim MM, Hussein S, El-Ghorab AH, Abdelgawad MA, et al. Repurposing of FDA Approved Alkaloids as COVID 19 Inhibitors; In Silico Studies. Pharmacog J. 2021;13(1): 110-23. 